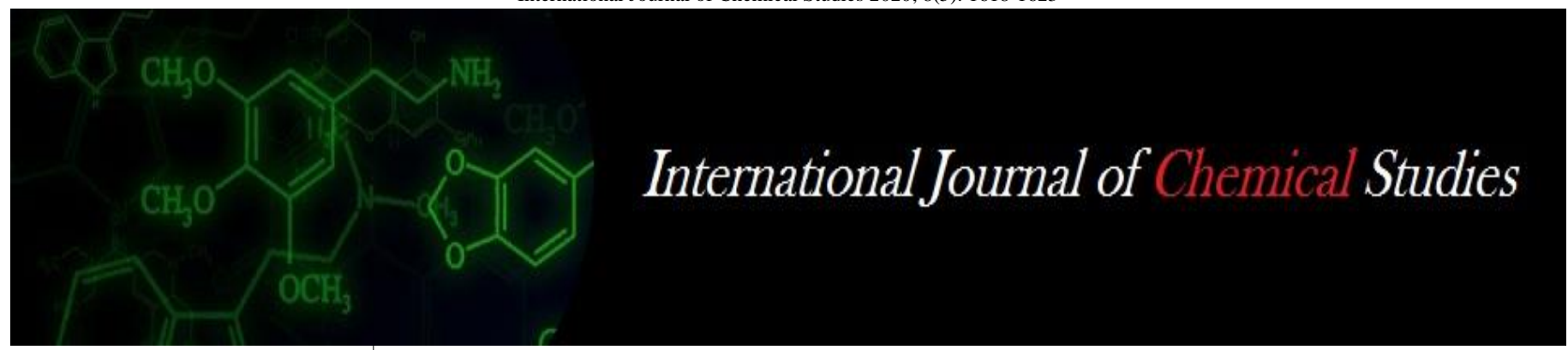

P-ISSN: 2349-8528

E-ISSN: 2321-4902

www.chemijournal.com

IJCS 2020; 8(5): 1618-1623

(C) 2020 IJCS

Received: 20-07-2020

Accepted: 26-08-2020

\section{BC Khodifad}

Research Scholar, Department

of Processing and Food

Engineering, College of

Agricultural Engineering and

Technology, Junagadh

Agricultural University,

Junagadh, Gujarat, India

\section{NK Dhamsaniya}

Principal, Polytechnic in Agro-

Processing, Junagadh

Agricultural University,

Junagadh, Gujarat, India

\section{PJ Rathod}

Assistant Professor, Department

of Biochemistry, Junagadh

Agricultural University,

Junagadh, Gujarat, India

\section{Effect of microwave drying on sensory attribute of coriander leaves}

\section{BC Khodifad, NK Dhamsaniya and PJ Rathod}

\author{
DOI: https://doi.org/10.22271/chemi.2020.v8.i5v.10534
}

\begin{abstract}
The current experiment was under taken to dry best quality coriander leaves using microwave drying. The response surface methodology was used to design and optimize the experimental treatment. The dried coriander leaves were analysed to obtain the changes in response of dependent variables of sensory attribute viz., colour, aroma, texture and overall acceptability due to varying the independent variables especially the microwave power level and drying time. The process variable for drying of coriander leaves optimized as microwave power level (70\%) and drying time ( $7 \mathrm{~min}$ and $23 \mathrm{~s}$ ). According to the optimized process variables, the validated responses were recorded as moisture content $2.05 \%$, colour value of 8.35 , aroma value of 7.28 , texture value of 8.34 and overall acceptability of 7.57 . The drying of coriander leaves using continuous microwave dryer is the best to get best quality dried coriander leaves with maximum retention of sensory attribute.
\end{abstract}

Keywords: Coriander leaves, microwave dryer, sensory attribute

\section{Introduction}

Coriander (Coriandrum sativum L.) is known as Dhania, Dhaniya, Kothamalli Kottambri, Dhane and Kastumbri. It belongs to the family of Apiaceae (Umbelliferae). Coriander has different names in different languages, i.e. English (coriander), Urdu (Dhania), Arabic (Kuzbara), Hindi (Dhania), Chinese (Yuan sui), Greek (korion) (Nadeem et al., 2013) [11]. Coriander is a native of Mediterranean region especially southern Europe and Asia minor. Precisely, Italy is preasumed as the native place of coriander (Singh and Nath, 2012) ${ }^{[17]}$. The coriander is extensively used in Middle Eastern, Mediterranean, Indian, South Asian, Latin American, Chinese, African and South-East Asian cuisine. Coriander is widely distributed in India. The main states in which coriander is grown on commercial scale in India are: Rajasthan, Madhya Pradesh, Maharashtra, Bihar, Gujarat, Uttar Pradesh, Punjab, Andhra Pradesh, Orissa, Tamil Nadu and Karnataka (Singhal, 1996) ${ }^{[18]}$. The seeds and dry leaves of coriander are used as a condiment purposes. Dried leaves and flowers are also used for flavouring of food (Katyal and Chadha, 1985) ${ }^{[5]}$. Green leafy vegetables are highly perishable with shelf-life of only few days owing to higher moisture which spoils around $30 \%$ of the produce. This calls for preservation and processing to prevent losses as well as make them available in the lean season at remunerative price. Vegetable can be processed and preserved by various methods among which drying is considered to be an important property that is unmatched by any other preservation techniques (Rajeswari, 2010; Patil et al., 2015) ${ }^{[14,12]}$. Drying is one of the oldest and traditional method of food preservation which is most widely used for food preservation. It converts the vegetable into light weight, easily transportable and storable product (Woodruff and Luh, 1986; Chauhan and Sharma, 1993) ${ }^{[20,3]}$. Major objective of drying is to remove moisture as quickly as possible at a temperature that does not seriously affect flavour, texture and colour of the food (Rajeswari, 2010) ${ }^{[14]}$. Several techniques are available, based on evaporation or freeze concentration. Thermal evaporation is the most common industrial technique (Sanchez et al., 2009) ${ }^{[16]}$. During microwave drying, these components are only exposed to low temperature and therefore suffer minimal thermal damage. It is, therefore, considered a mild concentration technique (Moreno et al., 2015; Petzold et al., 2009) ${ }^{[9,13]}$. Microwave drying has a potential for making superior quality produces while noticeably reducing drying duration (Bouraoui et al., 2006) ${ }^{[2]}$. Therefore, the present investigation was aimed to reduce the drying time and maintain the product quality of coriander leaves.
Corresponding Author: BC Khodifad

Research Scholar, Department

of Processing and Food

Engineering, College of

Agricultural Engineering and

Technology, Junagadh

Agricultural University,

Junagadh, Gujarat, India 


\section{Material and Methods \\ Raw material}

The fresh well-matured leaves of coriander required for drying were procured from the Instructional Farm of College of Agricultural Engineering and Technology, Junagadh Agricultural University, Junagadh (Gujarat, India). The leaves were arranged in $0.5 \mathrm{~kg}$ batches for different dying treatments.

\section{Experimental set-up}

Microwave drying of coriander leaves was accomplished in continuous microwave dryer $(3.7 \mathrm{~kW}$ microwave power system). The equipment consisted of $2 \mathrm{~m}$ long drying chamber of $0.3 \mathrm{~m}$ width having Teflon conveyor mesh belt. The coriander leaves pass through the continuous microwave power for drying was arranged in a single layer. A two-factor five-level Central Composite Rotatable Design (CCRD) with quadratic model was employed to study the combined effect of microwave power level and drying time on different response variables. A total of 14 combinations were carried out in random order according to a CCRD configuration for the two chosen variables with six centre points.

\section{Quality characteristic Moisture content}

The moisture content of coriander leaves was determined by hot air oven method as described by AOAC (2005) ${ }^{[1]}$. The sample was put in a pre-weighed petri dish. The weight of empty dish and dish with sample was noted separately. The sample loaded petri dishes were placed inside the hot air oven at $105 \pm 1{ }^{\circ} \mathrm{C}$ till it attained constant weight. The samples were cooled in a desiccator and weighed. The difference in the initial and final mass of sample was taken as the mass of water removed. The moisture content of pulp was expressed in percent wet basis and determined by the following formula,

Moisture content $(\%$, w. b. $)=\frac{\text { Mass of water removed, } g}{\text { Mass of sample taken, } g} \times 100$

\section{Sensory attribute}

The dried coriander leaves were analysed for retaining the sensory attributes. The changes in response of dependent variables of biochemical parameters viz., colour, aroma, texture and overall acceptability due to varying the independent variables especially the microwave power level and drying time were recorded. A panel of 10 semi trained panellists were asked to assess the dried sample and mark them on a hedonic rating test $(1=$ dislike extremely, $5=$ neither like nor dislike, and $9=$ like extremely) in accordance with their opinion for Colour, Aroma, Texture and Overall acceptability (Ranganna, 2000) ${ }^{[15]}$.

\section{Statistical analysis}

The statistical analysis of the experimental data was carried out to observe the effect of selected process variables on the various responses. The obtained data were subjected to analyse for graphical representation, analysis of variance (ANOVA) and multiple regression using the software package Design Expert version 10.0.7.0 (State-Ease Inc., Minneapolis, MN, USA). Based on the validated predictive models, a numerical optimizer helps the user to determine the ideal values for each of the factors in the experiment. The software determines the main effects of each factor as well as the interactions between factors by varying the values of all factors in parallel. The three-dimensional (3D) response surface plots was generated using Design Expert software. The effect and regression coefficients of individual linear, interaction and quadratic terms were determined from the ANOVA Table (Whitcomb and Anderson, 2004) ${ }^{[19]}$.

\section{Optimization and validation of process variables}

The optimization of process variables was carried out by using Design Expert version 10.0.7.0 software. The optimum values of the selected variables were analysed by the response surface and also by solving the regression equation. Using these optimized conditions the experiments were again conducted to find out the variation in the different response variable. The closeness of the predicted and observed responses indicated the validity of developed model.

\section{Results and Discussion}

The effect of the microwave power level and drying time on the sensory attribute of coriander leaves during drying was investigated. The data of different responses during continuous microwave drying of coriander leaves are presented in Table 1. The regression coefficients for various responses and the corresponding $\mathrm{R} 2$ and C.V. values are presented in Table 2 and Table 3. Analysis of variance indicated that the models are highly significant at $P<0.05$ for all the responses (Table 2). The R2 values for all responses were higher than 0.91, indicating the high accuracy and low proportion of the variability. Therefore, the models for all the responses were adequate. The general rule says that the coefficient of variation (C.V.) should not be more than $10 \%$. In this investigation, the C.V. for all the responses were obtained lower than 10.0 (Table 2 and Table 3 ). The adequate precision value of all the responses indicated that the model can be used to predict the response within the design space as it was greater than 4.0 (Montgomery, 2001) ${ }^{[8]}$.

\section{Moisture content}

Moisture content of dried coriander leaves was ranged between $9.15 \%$ to $79.25 \%$ during different treatment combinations. The minimum moisture content at $60 \%$ power level and 7.5 min drying time was about 8.66 times less than the maximum moiture content $79.25 \%$ at $20 \%$ power level and 4.5 min drying time (Table 1). The coefficient of model and other statistics are given in Table 2 . The model $\mathrm{F}$ value of 1057.98 implies that the model is significant $(P<0.05)$. R2 and adjusted R2 values of the model are 0.9985 and 0.9975 , respectively.

$$
\text { Moisture Content }=+120.20-0.67 \mathrm{~A}-3.11 \mathrm{~B}-0.038 \mathrm{AB}-0.00007 \mathrm{~A}^{2}-0.53 \mathrm{~B}^{2}
$$

As increase in microwave power level and drying time may reduce moisture content of coriander leaves. It can be observed from ANOVA (Table 2), linear terms of power level and drying time and quadratic term drying time are extremely significant. It may be observed from Fig. 1 (a) that moisture content of coriander leaves decreased with increase in microwave power level and drying time. It was happened due to increase in exposure time with increased drying time and also increase the magnitude of microwave energy (microwave power on time) with increase in microwave power level. Similar finding was observed for amaranth leaves dried by microwave energy at different microwave power level and 
drying time (Mujaffar and Loy, 2016) ${ }^{[10]}$. Also, the increase in microwave power level resulted increase in drying rates. Similar trend was observed by Maskan (2000) ${ }^{[7]}$ for drying of banana slices using the microwave.

\section{Colour}

The colour value of different drying treatment combinations are listed in Table 1. The value of colour was ranged from
4.00 to 8.11 . The maximum value was observed at $60 \%$ power level and 7.5 min drying time and minimum value was observed at $20 \%$ microwave power level and 4.5 min drying time. The maximum value was 2.03 time higher than the minimum value of colour value in given variable range. The detail statistic and coefficient of model terms are given in the Table 2.

$$
\text { Color }=+4.97-0.008 \mathrm{~A}-0.81 \mathrm{~B}+0.0065 \mathrm{AB}+0.0002 \mathrm{~A}^{2}+0.10 \mathrm{~B}^{2}
$$

The coefficients of model terms viz., power level and drying time are negative (Eq. 3). Therefore, increase in microwave power level and drying time may decrease the colour of coriander leaves. The coefficient of interaction and square terms are positive. It shows that the increase in microwave power level and drying time may increase the colour of coriander leaves. It may be due to combined effect of microwave power and drying time. The positive value of square model terms shows that the increase the concentration of colour at the higher microwave power level and drying time.

Table 2 shows that $\mathrm{F}$ values for linear terms of power level and drying time are extremely significant terms as compared to square term of $\mathrm{B} 2$ is 13.21 with $\mathrm{P}$ value of $0.007(P<0.01)$ showing that the term is also highly significant. From the Fig. 1 (b), it can be seen that the better colour of coriander leaves was obtained with increases in microwave power level and drying time. It may be due to increase in concentration of colour with corresponding to decrease in moisture content with microwave power level and drying time. Khodifad and Dhamsaniya (2020) [6] also reviewed that the microwave drying maintained a good green colour close to that of the original fresh green leaves with surface sterilization in most of the vegetables.

\begin{abstract}
Aroma
The aroma value of coriander was ranged from 5.00 to 7.33 (Table 1). The maximum value was observed at $100 \%$ power level and $4.5 \mathrm{~min}$ drying time and minimum value was observed at $20 \%$ microwave power level and 4.5 min drying time. The maximum value was 1.47 time higher than the minimum value of aroma value in given variable range. The other statistic and coefficient of model terms are given in the Table 2. The coefficient of interaction and square terms are positive (Eq. 4). Therefore, increase in microwave power level and drying time may increase the aroma of coriander leaves. It may due to combined effect of microwave power and drying time. The coefficients of square model terms are positive and it shows that the increase in excessive microwave power level and drying time may increase the aroma of coriander leaves.
\end{abstract}

$$
\text { Aroma }=+6.99-0.035 \mathrm{~A}-0.65 \mathrm{~B}+0.0065 \mathrm{AB}+0.00024 \mathrm{~A}^{2}+0.056 \mathrm{~B}^{2}
$$

Table 2 shows that $\mathrm{F}$ values for linear terms of power level and drying time are extremely significant terms. Whereas, the square term of B2 is comparatively less significant. From the Fig. 1 (c), it can be seen that the aroma of coriander leaves was increased with increases in microwave power level and drying time.
Texture: The texture value of different drying treatment combinations are listed in Table 1. The value of aroma was ranged from 3.89 to 8.00 . The maximum value was observed at $60 \%$ power level and 7.5 min drying time and minimum value was observed at $20 \%$ microwave power level and 4.5 min drying time.

$$
\text { Texture }=+4.47-0.005 \mathrm{~A}-0.65 \mathrm{~B}+0.0069 \mathrm{AB}+0.0002 \mathrm{~A}^{2}+0.084 \mathrm{~B}^{2}
$$

From the ANOVA, (Table 3 and Eq. 5) it can be seen that the linear terms of power level and drying time and square term B2 are extremely significant terms. Whereas the interaction term and square term A2 are less significant (Table 3). From the Fig. 1 (d), it can be seen that the texture of coriander leaves was increased with increases in microwave power level and drying time. The texture value of dried coriander leaves was observed inversely proportional with the moisture content of dried coriander leaves. As the moisture content decreases the texture of dried coriander leaves increase. The texture of microwave dried product retain very well because of the drying completed with mild heat treatment during microwave drying and without hot air flow.

Overall acceptability: The overall acceptability score of different drying treatment combinations are listed in Table1. The value of overall acceptability score was observed from 3.45 to 7.67 . The maximum value was observed at $100 \%$ power level and 4.5 min drying time and minimum value was observed at $20 \%$ microwave power level and 4.5 min drying time. Analysis of variance of Eq. 6 and Table 3 shows that the linear terms of power level and drying time are extremely significant terms.

$$
\text { Overall acceptabilty }=-0.64+0.084 \mathrm{~A}+0.52 \mathrm{~B}-0.0035 \mathrm{AB}-0.00014 \mathrm{~A}^{2}+0.021 \mathrm{~B}^{2}
$$


From the Fig. 1 (e), it can be seen that the overall acceptability of coriander leaves was increased with increases in microwave power level and drying time. It may be due to improve in colour and texture with decrease in moisture content of coriander leaves as drying progress which was liked to most of panelist.

\section{Optimization and validation of process variables}

The desired goals for each variable and responses were chosen with equal importance for optimization of process variables (Table 4). According to the goals that were fixed for variables, the optimum treatment combination were found to be, $71.00 \%$ microwave power level and $7 \mathrm{~min}$ and $21 \mathrm{~s}$ drying time. With this optimized variables, the predicted responses are given in Table 4. But, in independent variable particularly the microwave power level can be adjusted by the interval of $10 \%$ power level. So the nearest value of microwave power level as $70 \%$ was selected for target value and according to that the predicted responses are given in Table 4. It might be possible to produce coriander dried leaves with this treatment combination as moisture content of $1.90 \%$, colour value of 8.41 , aroma value of 7.34 , texture value of 8.43 and overall acceptability of 7.77 with a desirability of 1.0 (Table 4). Using these optimized conditions the drying experiment was again conducted to find the variation in the different responses. As per the results presented in Table 4, the experimental values of responses were very close to the predicted values (deviation<10\%). The closeness of the experimental and predicted responses indicated the validity of developed model.

These dried coriander leaves was remained complete as whole leaves and easily crushed. Similar kind of observation were reported by Mujaffar and Loy (2016) ${ }^{[10]}$ for drying of amaranth leaves and Kathirvel et al., (2006) ${ }^{[4]}$ for drying green leafy vegetables in batch type microwave oven.

Table 1: Quality parameters of coriander leaves with different treatment combination

\begin{tabular}{|c|c|c|c|c|c|c|c|}
\hline Treatment No. & Microwave power level & Drying time & \multicolumn{2}{|c|}{ Moisture content } & \multicolumn{3}{|c|}{ Sensory Attribute Oveall } \\
\hline & $(\boldsymbol{\%})$ & $(\mathbf{m i n})$ & \multicolumn{2}{c|}{$\boldsymbol{( \% )}$ wb) Colour } & Aroma & Texture & acceptability \\
\hline 1 & 80 & 6.0 & 12.50 & 7.33 & 6.67 & 7.52 & 7.18 \\
\hline 2 & 60 & 4.5 & 46.00 & 5.22 & 5.56 & 5.44 & 5.78 \\
\hline 3 & 60 & 7.5 & 9.15 & 8.11 & 7.00 & 8.00 & 7.56 \\
\hline 4 & 80 & 3.0 & 44.00 & 5.78 & 5.56 & 5.78 & 6.00 \\
\hline 5 & 60 & 4.5 & 44.50 & 6.00 & 5.67 & 5.56 & 5.89 \\
\hline 6 & 60 & 4.5 & 45.17 & 5.67 & 5.89 & 5.67 & 5.89 \\
\hline 7 & 40 & 6.0 & 47.00 & 5.11 & 5.78 & 5.13 & 5.44 \\
\hline 8 & 60 & 4.5 & 44.50 & 5.11 & 5.67 & 5.44 & 5.61 \\
\hline 9 & 60 & 4.5 & 44.00 & 5.33 & 5.89 & 5.67 & 5.78 \\
\hline 10 & 60 & 1.5 & 71.00 & 4.67 & 5.56 & 4.66 & 4.40 \\
\hline 11 & 100 & 4.5 & 10.18 & 7.56 & 7.33 & 7.89 & 7.67 \\
\hline 12 & 60 & 4.5 & 45.35 & 5.33 & 5.89 & 5.56 & 5.67 \\
\hline 13 & 20 & 4.5 & 79.25 & 4.00 & 5.00 & 3.89 & 3.45 \\
\hline 14 & 40 & 3.0 & 74.00 & 4.33 & 5.44 & 4.22 & 3.85 \\
\hline
\end{tabular}

Table 2: Analysis of variance for moisture content, colour and aroma of dried coriander leaves

\begin{tabular}{|c|c|c|c|c|c|c|c|c|c|}
\hline Coefficients & \multicolumn{3}{|c|}{ Moisture content } & \multicolumn{3}{|c|}{ Colour } & \multicolumn{3}{|c|}{ Aroma } \\
\hline & Coeff. Value & $\mathbf{F}$ & $\mathbf{P}$ & Coeff. Value & $\mathbf{F}$ & $\mathbf{P}$ & Coeff. Value & $\mathbf{F}$ & $\mathbf{P}$ \\
\hline Model & 120.20 & 1057.98 & $<0.0001$ & 4.97 & 36.77 & $<0.0001$ & 6.99 & 17.44 & 0.0004 \\
\hline \multicolumn{10}{|c|}{ Linear terms } \\
\hline A-Power level & $-0.67 * * *$ & 2905.90 & $<0.0001$ & $-0.008 * * *$ & 97.63 & $<0.0001$ & $-0.035 * * *$ & 47.71 & 0.0001 \\
\hline B-Drying time & $-3.11 * * *$ & 2349.12 & $<0.0001$ & $-0.81 * * *$ & 71.39 & $<0.0001$ & $-0.652 * * *$ & 27.91 & 0.0007 \\
\hline \multicolumn{10}{|c|}{ Interaction terms } \\
\hline $\mathrm{AB}$ & -0.038 & 4.30 & 0.0719 & 0.0065 & 1.51 & 0.2539 & 0.0065 & 2.72 & 0.1379 \\
\hline \multicolumn{10}{|c|}{ Quadratic terms } \\
\hline $\mathrm{A} 2$ & -0.00007 & 0.018 & 0.8968 & 0.0002 & 1.54 & 0.2491 & 0.00024 & 4.12 & 0.0768 \\
\hline B2 & $-0.53 * * *$ & 29.07 & 0.0007 & $0.10 * *$ & 13.21 & 0.007 & $0.056^{*}$ & 6.80 & 0.0313 \\
\hline $\mathrm{R} 2$ & 0.9985 & & & 0.9583 & & & 0.9160 & & \\
\hline C.V. $\%$ & 2.46 & & & 5.54 & & & 4.00 & & \\
\hline Adjusted R2 & 0.9975 & & & 0.9322 & & & 0.8635 & & \\
\hline Adequate Precision & 96.819 & & & 19.137 & & & 12.184 & & \\
\hline
\end{tabular}

Table 3: Analysis of variance for colour, aroma, texture and overall acceptability of dried coriander leaves

\begin{tabular}{|c|c|c|c|c|c|c|}
\hline \multirow{2}{*}{ Coefficients } & \multirow[b]{2}{*}{ Coeff. Value } & \multirow{2}{*}{$\begin{array}{c}\text { Texture } \\
\text { F }\end{array}$} & \multirow[b]{2}{*}{$\mathbf{P}$} & \multicolumn{3}{|c|}{ Overall acceptability } \\
\hline & & & & Coeff. Value & $\mathbf{F}$ & $\mathbf{P}$ \\
\hline Model & 4.47 & 153.60 & $<0.0001$ & -0.64 & 184.64 & $<0.0001$ \\
\hline \multicolumn{7}{|c|}{ Linear terms } \\
\hline A-Power level & $-0.005 * * *$ & 451.58 & $<0.0001$ & $0.084 * * *$ & 591.31 & $<0.0001$ \\
\hline B-Drying time & $-0.65 * * *$ & 276.25 & $<0.0001$ & $0.52 * * *$ & 321.60 & $<0.0001$ \\
\hline \multicolumn{7}{|c|}{ Interaction terms } \\
\hline $\mathrm{AB}$ & $0.0067 *$ & 6.56 & 0.0336 & -0.0035 & 2.03 & 0.1920 \\
\hline \multicolumn{7}{|c|}{ Quadratic terms } \\
\hline A2 & $0.0002 *$ & 5.69 & 0.0442 & -0.00014 & 3.67 & 0.0917 \\
\hline B2 & $0.084 * * *$ & 32.56 & 0.0005 & 0.021 & 2.59 & 0.1459 \\
\hline
\end{tabular}




\begin{tabular}{|c|c|c|c|c|c|c|}
\hline R2 & 0.9897 & & & 0.9914 & & \\
\hline C.V.\% & 2.82 & & & 5.73 & & \\
\hline Adjusted R2 & 0.9832 & & & 0.9860 & & \\
\hline Adequate Precision & 37.53 & & & 42.891 & & \\
\hline
\end{tabular}

Level of Significance: $* P<0.05, * * P<0.01, * * * P<0.001$, ns: not significant; df: degrees of freedom

Table 4: Optimized and validated of process variables for drying of coriander leaves

\begin{tabular}{|c|c|c|c|c|c|c|}
\hline \multicolumn{4}{|c|}{ Variables } & \multicolumn{3}{|c|}{ Variables for targeted microwave power level } \\
\hline & Goal & Importance & Optimum value & Goal & Importance & $\begin{array}{l}\text { Optimum } \\
\text { value }\end{array}$ \\
\hline Microwave power level (\%) & In the range & 3 & 71 & Targeted & 3 & 70 \\
\hline Drying time (min) & In the range & 3 & $7 \min 21 \mathrm{~s}$ & In the range & 3 & $7 \mathrm{~min}$ and $23 \mathrm{~s}$ \\
\hline \multicolumn{4}{|c|}{ Responses } & \multicolumn{3}{|c|}{ Responses for targeted microwave power level } \\
\hline Constraints & Goal & Importance & Predicted value & Predicted value & Experimental value & Deviation (\%) \\
\hline Moisture content $(\%)$ & Minimum & 3 & 1.47 & 1.90 & 2.05 & 7.89 \\
\hline Colour & Maximum & 3 & 8.43 & 8.41 & 8.35 & 0.71 \\
\hline Aroma & Maximum & 3 & 7.36 & 7.34 & 7.28 & 0.81 \\
\hline Texture & Maximum & 3 & 8.46 & 8.43 & 8.34 & 1.06 \\
\hline Overall acceptability & Maximum & 3 & 7.78 & 7.77 & 7.57 & 2.57 \\
\hline
\end{tabular}

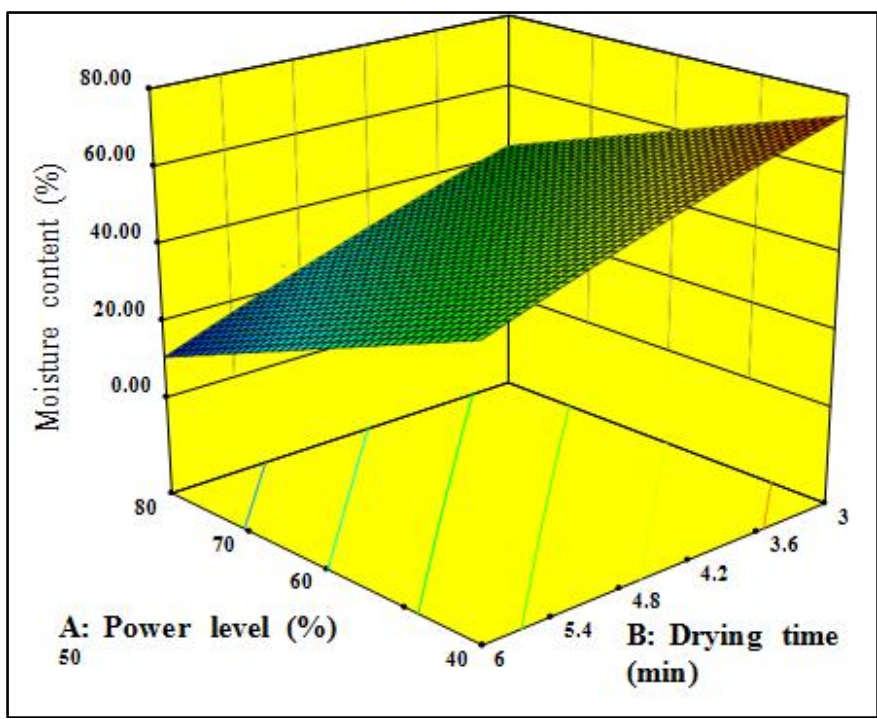

A. Moisture content

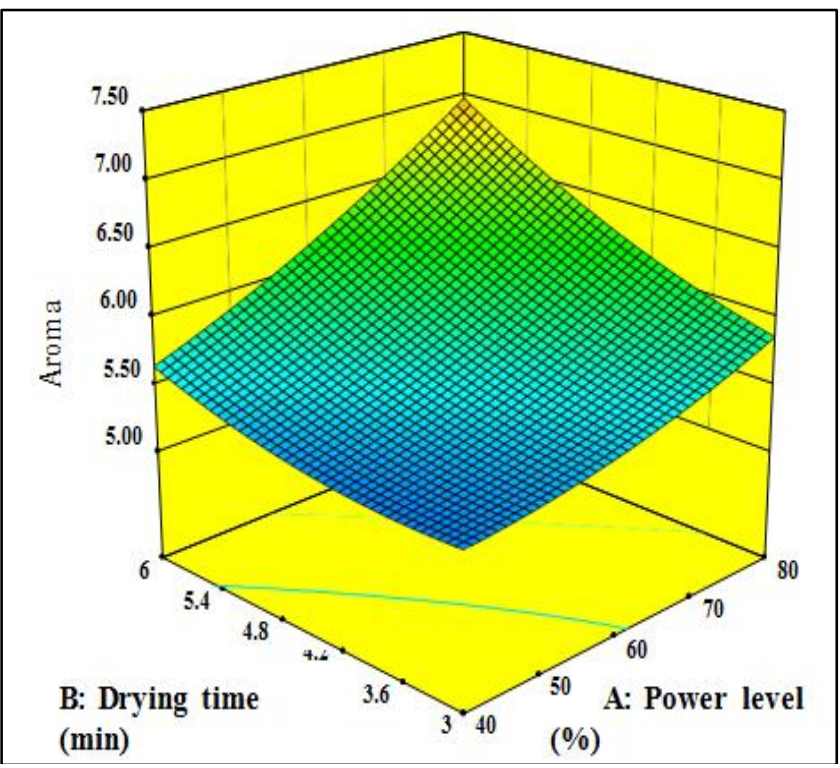

C. Aroma

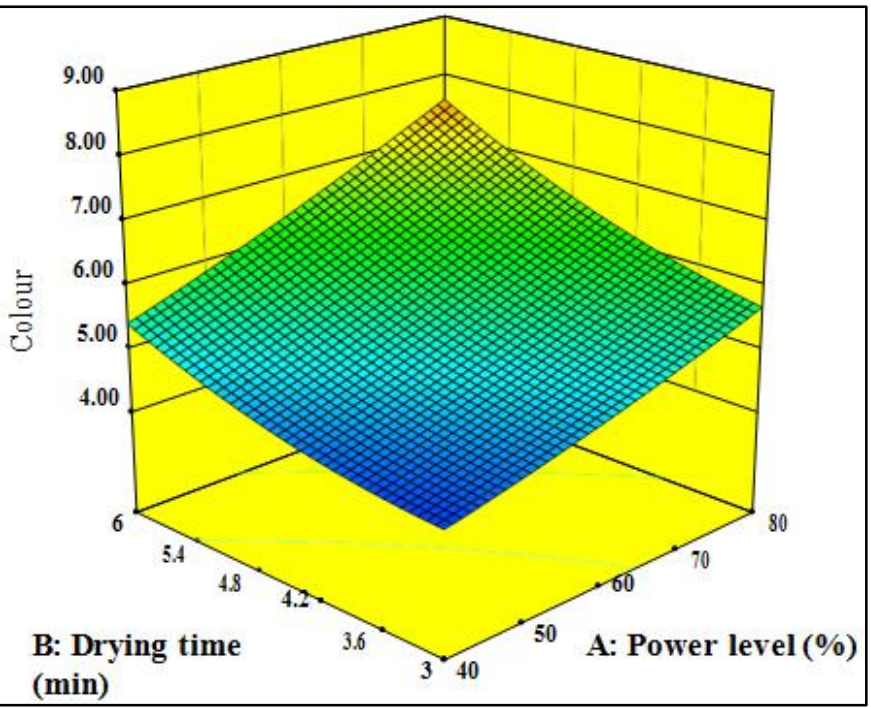

B. Colour

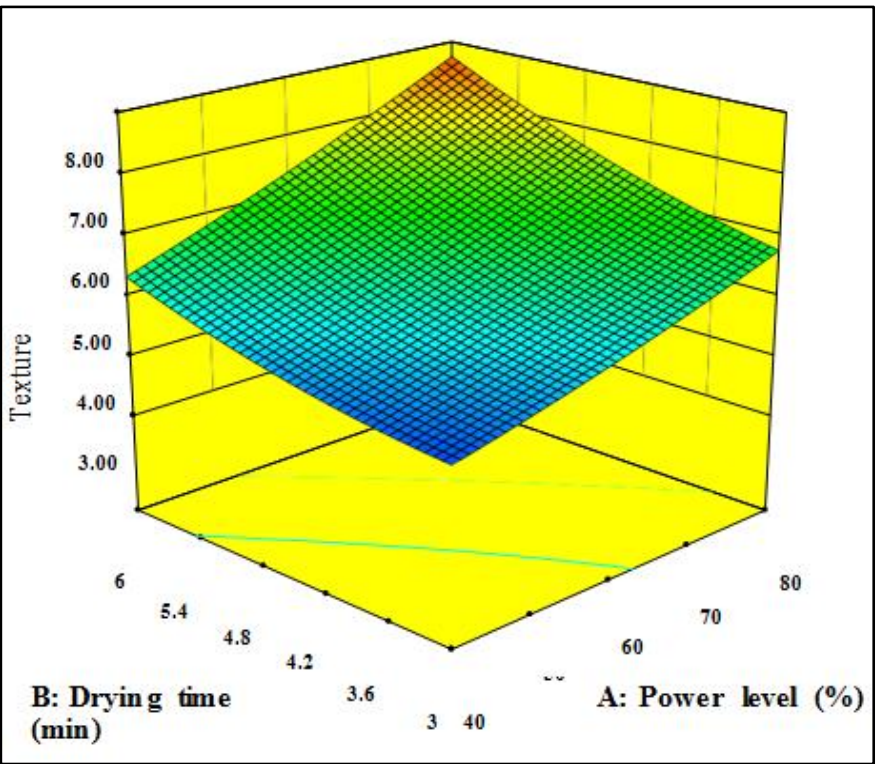

D. Texture 


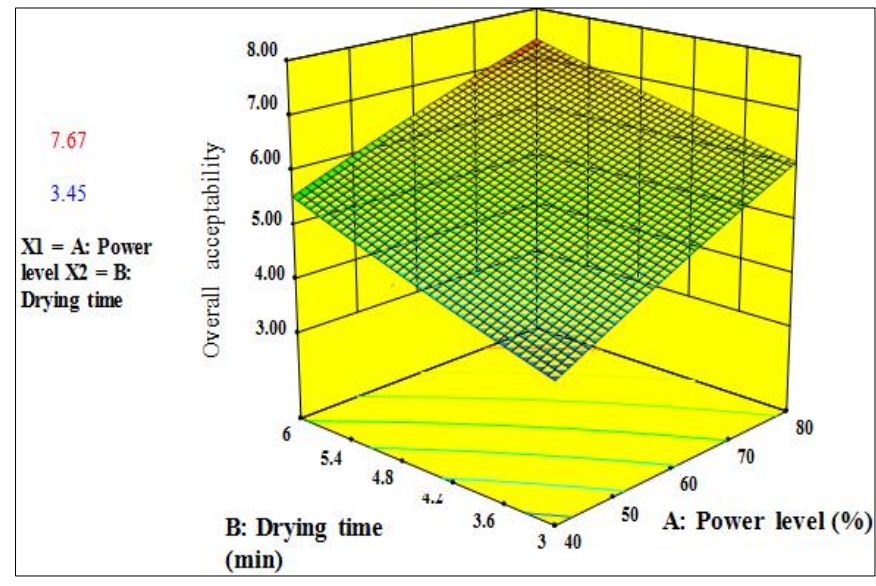

E. Overall acceptability

Fig 1: Variation in sensory atrribute of coriander leaves with changing in microwave power level and drying time

\section{Conclusion}

The process variable for drying of coriander leaves optimized as microwave power level $(70 \%)$ and drying time (7 min and $23 \mathrm{~s})$. According to the optimized process variables, the validated responses were recorded as moisture content $2.05 \%$, colour value of 8.35 , aroma value of 7.28 , texture value of 8.34 and overall acceptability of 7.57. The drying of coriander leaves using continuous microwave dryer is the best to get best quality dried coriander leaves with maximum retention of sensory attribute. The leaves dried by continuous microwave dryer remained complete as whole and it can be easily crushed and converted in to a powder.

\section{Reference}

1. AOAC. Official Methods of Analysis of the AOAC International, 18th ed., Gaithersburg, MD, USA, 2005.

2. Bouraoui M, Richard P, Durance T. Microwave and convective drying of potato slices. J Food Process Eng. 2006; 17(3):353-363. DOI: $10.1111 /$ j.17454530.1994.tb00343.x

3. Chauhan SK, Sharma CR. Development of instant dehydrated saag. Beverages and Food World. 1993; 20(4):25-26.

4. Kathirvel K, Naik KR, Gariepy Y, Orsat V, Raghavan G. SV Microwave drying-a promising alternative for the herb processing industry. In 2006 ASABE Annual Meeting, 2006, 1.

5. Katyal SL. Chadha KL. Vegetable growing in India. Oxford and IBH Publishing Compny, New Delhi, 1985.

6. Khodifad, B. C. and Dhamsaniya, N. K. Drying of Food Materials by Microwave Energy-A Review. Int. J Curr. Microbiol. App. Sci. 2020; 9(5):1950-1973.

7. Maskan M. Microwave/air and microwave finish drying of banana. J Food Eng. 2000; 44(2):71-78. DOI: 10.1016/S0260-8774(99)00167-3.

8. Montgomery DC. Design and analysis of experiments (5th Edn). New York: John Wiley, 2001, 455-492.

9. Moreno FL, Quintanilla-Carvajal MX, Sotelo LI, Osorio C, Raventos M, Hernandez E. Volatile Compounds, Sensory Quality and Ice Morphology in Falling- Film and Block Freeze Concentration of Coffee Extract. J Food Eng. 2015; 166:64-71.

10. Mujaffar S, Loy AL. Drying kinetics of microwave-dried vegetable amaranth (Amaranthus dubius) leaves. J Food Res. 2016; 5(6):33-44.

11. Nadeem M, Muhammad AF, Khan M, Tehseen S, ElGhorab A, Sultan JI. Nutritional and medicinal aspects of coriander (Coriandrum sativum L.) A review. British Food Journal. 2013; 115(5):743-755.

12. Patil GD, Pardeshi IL, Shinde KJ. Drying of green leafy vegetables using microwave oven dryer. Journal Ready to Eat Food. 2015; 2:18-26.

13. Petzold G, Aguilera JM. Ice Morphology: Fundamentals and Technological Applications in Foods. Food Biophys. 2009; 4:378-396.

14. Rajeswari R. Dehydration of green leafy vegetables and its effect on quality. M.H.Sc. Dissertation, University of Agricultural Sciences, Dharwad, India, 2010.

15. Ranganna S. Handbook of analysis and quality control for fruit and vegetable products. (6th Edn). New Delhi: Tata McGraw-Hill Publishing Co. Ltd, 2000.

16. Sanchez J, Ruiz Y, Auleda JM, Hernandez E, Raventos M. Review. Freeze Concentration in the Fruit Juices Industry. Food Sci. Technol. Int. 2009; 15:303-315.

17. Singh DN, Nath V. Winter Vegetables Advances and Developments. Satish Serial Publishing House, 2012, 505-527.

18. Singhal V. Coriander. In Indian Agriculture. Indian Economics Data Centre. New Delhi, 1996, 528-529.

19. Whitcomb PJ, Anderson MJ. RSM simplified: optimizing processes using response surface methods for design of experiments. CRC press. New York, 2004.

20. Wood Ruff JG, Luh B. Commercial fruit processing, 2nd edition. AVI Publishers. USA, 1986. 